\title{
Elemente und Ephemeride des Cometen 1882 Barnard.
}

Die Bahn wurde erhalten aus den Beobachtungen zu Harvard College Sept. I4 und den Kieler Beobachtungen von Sept. 16 und 19. Die genaue Position des Vergleichsterns zur Beobachtung Sept. I 6 wurde mir freundlichst von Herrn Professor Bruns in Leipzig mitgetheilt.

$$
\begin{aligned}
& T=1882 \text { Nov. } 12.9497 \text { m. Z. Berlin } \\
& \pi-\delta=253^{\circ} 38^{\prime} 4^{\prime \prime} \\
& \left.\delta=\begin{array}{llll}
249 & 8 & 24
\end{array}\right\} \text { M. Aeq. I } 882.0 \\
& i=953035 \\
& \log q=9.98446
\end{aligned}
$$

Darst. der mittl. Beob. $\Delta \lambda \cos \beta=+4$ "

$$
\Delta \beta=-4 "
$$

Ephemeride für I $^{\text {h }}$ M. Z. Berlin.

\begin{tabular}{|c|c|c|c|c|c|c|c|c|c|}
\hline 1882 & M. Z. Kiel & $\Delta a$ & $\Delta \delta$ & Vgl. & $\alpha$ app. & $\log p .4$ & $\delta$ app. & $\log p .4$ & $*$ \\
\hline Sept. 19 & $16^{\mathrm{h}} 10^{\mathrm{m}} 19^{\mathrm{s}}$ & $+0^{m} 7^{5} \cdot 03$ & $-5^{\prime} 47^{\prime \prime} 8$ & 14.4 & $7^{h} 28^{m} 55^{s}: 85$ & $9 \cdot 43^{6} \mathrm{n}$ & $+12^{\circ} \circ^{\prime} 5^{\prime \prime} \cdot 3$ & 0.900 & 2 \\
\hline 20 & I $5 \begin{array}{lll}29 & 39\end{array}$ & +3 I 1.48 & +220.7 & $5 \cdot 5$ & $7 \quad 30 \quad 57.30$ & $9.485 n$ & + I I 654.5 & 0.8 I 6 & 3 \\
\hline
\end{tabular}

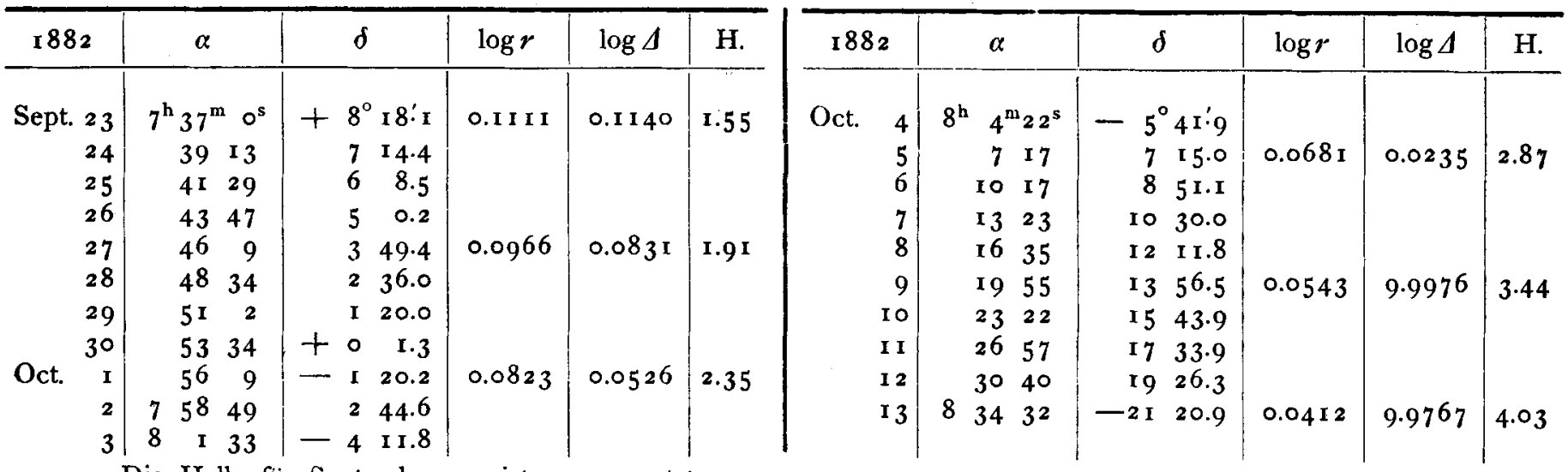

Die Helle für September 14 ist $=1$ gesetzt.

\begin{tabular}{|c|c|c|c|c|c|}
\hline * & $\alpha \mathrm{I} 882.0$ & & & $\delta$ I 88.2.0 & $A u t o r i t \ddot{a} t$ \\
\hline 2 & $7^{\mathrm{h}} 25^{\mathrm{m}} 46^{\mathrm{s}} .07$ & +2.55 & $+12^{\circ}$ & $633.9-7.8$ & Bessel Zone 148. \\
\hline 3 & $\begin{array}{lll}7 & 27 & 43.05\end{array}$ & +2.77 & $+\mathbf{I} \mathbf{I}$ & $441.2-7.4$ & $>\quad>$ \\
\hline
\end{tabular}

Berlin I 882 Sept. I 9.

Dr. H. Oppenheim.

Beobachtungen des Cometen 1882 Barnard auf der Kieler Sternwarte. (Fortsetzung.)

Mittlere Oerter der Vergleichterne.

Sept. 19. Der Comet war etwas schwierig zu beobachten, da die lichtschwache nebelige Masse bei dem Antritt an den erleuchteten Faden während I-2 Secunden vollständig verschwand; die Declination liess sich verhältnissmässig sicherer auffassen und wird weniger einer constant fehlerhaften Auffassung ausgesetzt sein, als die Rectascension.

Zu der Beobachtung Sept. I6 (A. N. 2454) erhielt ich durch Herrn Prof. Bruns den Ort des Vergleichsternes nach 2 Leipziger Mer.-Beobachtungen 1882.0: $7^{\mathrm{h}} 22^{\mathrm{m}} 3^{2} .99+14^{\circ} 35^{\prime} 5^{6} \cdot 6^{\prime \prime} \mathrm{o}$, wonach der scheinbare Ort des Cometen: 72250.43 +14 3731.4 .

Kiel 1882 Sept. 21 .

A. Krueger.

\section{In h alt:}

Zu Nr. 2457. Antonio Abetti. Sugli elementi dell' orbita del pianeta (170) Maria. 129. - F, F. Fulius Schmidt. Beobachtungen des Cometen 1882 Wells nach dem Perihel. 131. $-B$. v. Engelhardt. Planetenbeobachtungen. 137. - H. Oppenheim. Elemente und Ephemeride des Cometen 1882 Barnard. 143. - A. Krueger. Beobachtungen des Cometen 1882 Barnard auf der Kieler Sternwarte. (Forts.). 143. Gesehlossen 1882 Sept. 22. Herausgeber: A. Krueger. Druck ron C. F. Mo hr. Expedition: Sternwarte in Kiel. 